\title{
The shape of the DNA minor groove directs binding by the DNA-bending protein Fis
}

\author{
Stefano Stella, ${ }^{1}$ Duilio Cascio, ${ }^{2}$ and Reid C. Johnson ${ }^{1,3,4}$ \\ ${ }^{1}$ Department of Biological Chemistry, David Geffen School of Medicine at the University of California at Los Angeles, Los \\ Angeles, California 90095-1737, USA; ${ }^{2}$ Univerity of California at Los Angeles-Department of Energy Institute of Genomics and \\ Proteomics, University of California at Los Angeles, Los Angeles, California 90095-1570, USA; ${ }^{3}$ Molecular Biology Institute, \\ University of California at Los Angeles, Los Angeles, California 90095, USA
}

The bacterial nucleoid-associated protein Fis regulates diverse reactions by bending DNA and through DNAdependent interactions with other control proteins and enzymes. In addition to dynamic nonspecific binding to DNA, Fis forms stable complexes with DNA segments that share little sequence conservation. Here we report the first crystal structures of Fis bound to high- and low-affinity 27-base-pair DNA sites. These 11 structures reveal that Fis selects targets primarily through indirect recognition mechanisms involving the shape of the minor groove and sequence-dependent induced fits over adjacent major groove interfaces. The DNA shows an overall curvature of $\sim 65^{\circ}$, and the unprecedented close spacing between helix-turn-helix motifs present in the apodimer is accommodated by severe compression of the central minor groove. In silico DNA structure models show that only the roll, twist, and slide parameters are sufficient to reproduce the changes in minor groove widths and recreate the curved Fis-bound DNA structure. Models based on naked DNA structures suggest that Fis initially selects DNA targets with intrinsically narrow minor grooves using the separation between helix-turn-helix motifs in the Fis dimer as a ruler. Then Fis further compresses the minor groove and bends the DNA to generate the bound structure.

[Keywords: DNA structure; protein-DNA recognition; DNA bending; nucleoid protein; X-ray crystallography]

Supplemental material is available at http://www.genesdev.org.

Received December 28, 2009; revised version accepted March 3, 2010.

DNA-binding proteins can broadly be divided into those that recognize their DNA-binding sites with high sequence discrimination, and those that bind DNA with little or no obvious sequence preference. Members of the latter class are often present in much higher copy number than sequence-specific control proteins, participate in diverse DNA reactions, and act as DNA architectural factors by deforming the DNA helix. Examples include the nucleoid-associated proteins Fis (Factor for Inversion Stimulation), IHF, HU, and H-NS in eubacteria, chromatinassociated proteins like the HMGB family, and histones in eukaryotes. Along with physiologically significant binding to random sequence DNA, many bind preferentially to specific targets and regulate gene expression, DNA recombination, and chromosome packaging. Because these targets can vary widely in their base sequence, indirect recognition mechanisms involving poorly understood intrinsic properties of DNA structure are believed to direct binding.

${ }^{4}$ Corresponding author.

E-MAIL rcjohnson@mednet.ucla.edu; FAX (310) 206-5272.

Article is online at http://www.genesdev.org/cgi/doi/10.1101/gad.1900610.
Fis is one of the most abundant DNA-binding proteins in enteric bacteria under rapid growth conditions (Ball et al. 1992). Fis compacts DNA by its nonspecific DNAbinding and DNA-bending properties, and can actively condense long segments of DNA by stabilizing DNA loops in vitro (Skoko et al. 2006). Although Fis can indiscriminately bind and coat DNA with nanomolar affinity, it forms stable complexes with specific DNA sequences (Fig. 1A). Stable Fis-binding sequences are often found in intergenic or other regulatory regions, consistent with its role as a global regulator of DNA transactions (Finkel and Johnson 1992; Johnson et al. 2005; Travers and Muskhelishvili 2005; Dorman 2009). Fis was originally identified because it is required for site-specific recombinases like Hin and Gin to catalyze inversion of DNA segments; hence its full name, Factor for Inversion Stimulation. It also functions in integration-excision reactions of phages, as a positive or negative regulator of transcription, and in cell cycle timing of chromosome replication. Molecular analyses of these diverse reactions have shown that Fis functions both by cooperatively interacting with different effectors such as RNA polymerase, recombinases, and other control proteins, and by bending DNA. 
A

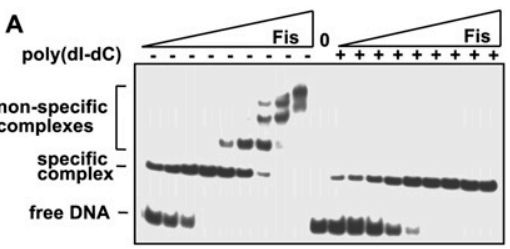

B

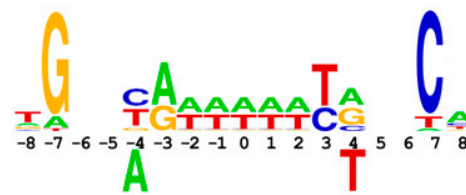

C

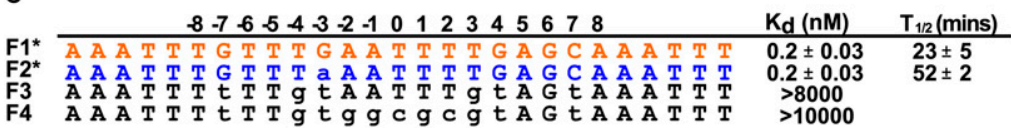

Figure 1. DNA binding by Fis. (A) EMSA showing binding to a 97-bp fragment containing the F1 site in the presence or absence of competitor DNA [50 $\mu \mathrm{g} /$ $\mathrm{mL}$ poly $(\mathrm{dI} \cdot \mathrm{dC})]$ with fourfold increasing amounts of Fis beginning at $0.005 \mathrm{nM}$. Fis generates an additional three nonspecifically bound complexes on the same DNA fragment without competitor DNA. (B) Sequence logo qualitatively depicting the degenerate Fis-binding motif based on compilations of native Fis-binding sites, SELEX experiments, and mutagenesis (Finkel and Johnson 1992; Hengen et al. 1997; Ussery et al. 2001; Cho et al. 2008; Shao et al. 2008b). Bases denoted below the numbers are inhibitory for binding. (C) Sequence of the 27-bp optimal F1 and F2 sites used for crystallography and nonconsensus sites F3 (AT center) and F4 (GC center). In this and subsequent figures, sequences where crystal structures of Fis complexes were determined are demarked with an asterisk, and differences from the F1 sequence are in lowercase. Fis-binding affinities $\left(\mathrm{K}_{\mathrm{d}}\right)$ with standard deviations and dissociation rates $\left(\mathrm{T}_{1 / 2}\right)$ for the 27-bp oligonucleotides are shown.

High-affinity Fis-binding sites are poorly related at the primary sequence level, but 15-base-pair (bp) segments are sufficient to specify stable Fis-binding sites when embedded in a longer sequence (Bruist et al. 1987). Highly degenerate 15-bp consensus sequences for Fis binding have been derived by aligning many high-affinity binding sites with respect to their nuclease and chemical reactivity in footprinting experiments (Hubner and Arber 1989; Finkel and Johnson 1992; Hengen et al. 1997; Ussery et al. 2001), and more recently from SELEX (Shao et al. 2008b) and whole-genome chromatin immunoprecipitation (ChIP)-chip analyses (Fig. 1B; Cho et al. 2008). These studies all point to a $\mathrm{G}-13 \mathrm{bp}-\mathrm{C}$ motif, with the central 5-7 bp being AT-rich. The 27-bp F1 and F2 oligonucleotides that contain the optimal binding sequences that are used for crystallography in this study form complexes with Fis with $10^{5}$ greater affinity than anti-consensus sequences F3 or F4 (Fig. 1A,C).

Previous experiments have implied that the DNA within Fis complexes is curved from $50^{\circ}$ to $90^{\circ}$, with the variability largely determined by the sequences flanking the 15-bp core motif (Pan et al. 1994, 1996; Perkins-Balding et al. 1997). Structures of unbound Fis in five crystal forms have revealed that the C-terminal $\mathrm{C}$ and $\mathrm{D}$ helices of each Fis subunit are folded into a helixturn-helix (HTH) DNA-binding motif (Kostrewa et al. 1991; Yuan et al. 1991; Safo et al. 1997; Cheng et al. 2000). However, the distance between recognition helices in the apodimer is only $\sim 25 \AA$, or almost $10 \AA$ shorter than the pitch of normal B DNA. Unlike the Trp and Tet repressors, whose apo forms also contain their recognition helices spaced inappropriately for DNA binding, the Fis protein structure does not change upon DNA binding (Merickel et al. 2002; this study).

In this study, we report the first crystal structures that show how different DNA sequences adapt to the Fisbinding surface. The 11 Fis-DNA crystal structures reveal that radical fluctuations in DNA minor groove width and sequence-dependent bending are key determinants in complex formation. We model DNA structures to dissect which structural parameters are responsible for molding the DNA to bind Fis, and use values based on naked DNA crystal structures to predict binding strength based on minor groove shape. Taken together, these findings suggest a binding mechanism by which Fis initially selects DNA targets based on the intrinsic width of the minor groove, followed by an induced fit by the DNA.

\section{Results}

\section{Fis-DNA crystals and structure determination}

Fis binding to duplex DNA oligonucleotides of increasing lengths extending from the 15-bp motif was evaluated first by gel mobility shift assays. Weak binding begins with 2 bp of flanking DNA on each side (19 bp), and highaffinity binding occurs with a 21-bp duplex containing three flanking base pairs (Pan et al. 1996; data not shown). Cocrystallization trials of Fis and DNAs between 21 and 31 bp gave the best crystals with 27-bp blunt-ended sequences containing AT-rich sequences flanking the 15-bp core. Structures of complexes containing the related F1 and F2 sequences were independently phased and refined at a resolution of $2.9 \AA$ with $\mathrm{R}_{\mathrm{w}} / \mathrm{R}_{\mathrm{f}}$ of $20.1 / 24.0$ and 21.4 / 26.3, respectively (Table 1). Crystals of Fis complexes with nine other related DNA sequences were also obtained, and their structures were solved by molecular replacement using the Fis-F1 structure (Supplemental Table S1).

\section{Overall structure of the Fis-DNA complex}

Surprisingly few intermolecular contacts stabilize the lattice within the crystals, consistent with their modest diffraction resolution. The DNA duplexes are aligned end-to-end to form a serpentine helix through the crystal lattice (Fig. 2B). The bases from each molecule are well stacked at their junctions, but the DNA backbones veer away from each other to avoid clashing (Fig. 2C). Additional interactions between Fis-DNA units involve the $\mathrm{N}$-terminal $\beta$-hairpin arms (Fig. 2D), which function to activate DNA invertases like Hin (Koch et al. 1991; Osuna et al. 1991; Safo et al. 1997). The Fis-DNA crystals provide a second form where the entire $\beta$-hairpin arm region (residues 1-27 from subunit A, 10-26 from subunit B) can be traced. Alignment of the Fis-DNA structure 
Table 1. Data collection and refinement statistics

\begin{tabular}{|c|c|c|}
\hline Structure & Fis-F1 & Fis-F2 \\
\hline PDB code & $3 I V 5$ & 3JR9 \\
\hline \multicolumn{3}{|l|}{ Data collection } \\
\hline Space group & $\mathrm{P} 2_{1} 2_{1} 2_{1}$ & $\mathrm{P} 2_{1} 2_{1} 2_{1}$ \\
\hline Unit cell dimensions $(\AA ̊)$ & $\begin{array}{l}a=43.08 \\
b=92.98 \\
c=154.51\end{array}$ & $\begin{array}{l}a=42.96 \\
b=91.69 \\
c=154.17\end{array}$ \\
\hline Resolution range $(\AA)$ & $90.0-2.9(3.0-2.9)$ & $90.0-2.9(3.0-2.9)$ \\
\hline Completeness (\%) & $98.7(90.7)$ & $99.0(99.4)$ \\
\hline Redundancy & $7.0(5.3)$ & $3.2(3.2)$ \\
\hline$R_{\mathrm{sym}}(\%)$ & $9.2(65.7)$ & $16.5(66.8)$ \\
\hline $\mathrm{I} / \sigma \mathrm{I}$ & $17.9(1.6)$ & $9.6(1.3)$ \\
\hline \multicolumn{3}{|l|}{ Refinement } \\
\hline$\overline{\text { Resolution }}(\AA)$ & 2.9 & 2.9 \\
\hline Number of reflections & 12,504 & 11,992 \\
\hline$R_{\text {work }}$ & 20.1 & 21.4 \\
\hline$R_{\text {free }}$ & 24.0 & 26.3 \\
\hline Bond lengths $(\AA)$ & 0.014 & 0.01 \\
\hline Bond angles $\left({ }^{\circ}\right)$ & 1.8 & 1.64 \\
\hline \multicolumn{3}{|l|}{ Number of atoms } \\
\hline Protein & 1505 & 1521 \\
\hline DNA & 1101 & 1101 \\
\hline Water & 12 & 22 \\
\hline \multicolumn{3}{|l|}{$B$-factors } \\
\hline Protein & 31.35 & 32.87 \\
\hline DNA & 56.07 & 54.6 \\
\hline \multicolumn{3}{|l|}{$\underline{\text { Ramachandran statistics }}$} \\
\hline Core $(\%)$ & 89.5 & 91.2 \\
\hline Allowed (\%) & 10.5 & 8.8 \\
\hline Generously allowed (\%) & 0 & 0 \\
\hline
\end{tabular}

Values in parentheses refer to the highest resolution shell. High $R_{\text {sym }}$ values in the last shell are due to crystal anisotropy.

with three earlier crystal structures of mutant Fis proteins with partial or intact $\beta$-hairpin arm segments resolved (Supplemental Fig. S1), plus solution cysteine cross-linking experiments, show that the $\beta$-hairpin arms are flexible (Safo et al. 1997; Cheng et al. 2000).

The C-terminal D helix representing the recognition helix of the HTH unit of each subunit is inserted into adjacent major grooves on the concave side of the curved DNA (Fig. 2A). The separation of the HTH motifs remains identical between the bound and the unbound forms; alignment of the four $\alpha$-helices of Fis bound to DNA with unbound Fis (1ETY) gives a root mean square deviation (RMSD) of $0.43 \AA$ (peptide backbone atoms) (Supplemental Fig. S2). The absence of a change in the Fis structure upon binding is consistent with previous FRET-based experiments and binding studies with disulfide-linked dimers (Merickel et al. 2002). In contrast, the DNA undergoes substantial conformational adjustments to fit onto the binding surface of Fis.

\section{DNA conformational changes}

The overall curvatures of the DNA in the F1 and F2 complexes are $\sim 65^{\circ}$ (Supplemental Fig. S3), which corresponds well with Fis-induced DNA-bending angles measured by gel electrophoresis and Fis-chemical nuclease chimeras (Pan et al. 1994, 1996; Perkins-Balding et al. 1997). Dinucleotide steps between -7 to -3 and +3 to +7 in the two major groove interfaces all exhibit positive roll deviations with two modest kinks located at base pairs $\pm(6-7)$ and $\pm(3-4)$ (Fig. 3A,B). The $\mathrm{G}_{-7}-\mathrm{T}_{-6}$ steps contain $13^{\circ}-17.5^{\circ}$ bends, whereas the $\mathrm{G}_{+6}-\mathrm{C}_{+7}$ steps contain $9^{\circ}-$ $10^{\circ}$ bends in the F1 and F2 structures (Fig. 3A). These bends are promoted by contacts with Arg85 to the conserved guanines (discussed below). The $7.5^{\circ}-10.5^{\circ}$ bends at $\pm(3-4)$ are at a dinucleotide step that influences Fis binding through indirect means. The DNA is underwound over the major groove interfaces, with an average twist of $31^{\circ}$ over the segments between $\pm(3-8)$ in the F1 and F2 structures. The average twist values over the 21-bp interface with the protein are $34.4^{\circ}$, which corresponds to linear DNA with a 10.5-bp/turn helical repeat.

The central 7 bp $(-3$ to +3$)$ are remarkably straight, with overall curvatures of $3.5^{\circ}$ (F1) and $4^{\circ}$ (F2) (Fig. 3A,B). The minor groove over this region is severely compressed, shrinking to almost half the width of canonical DNA at the center (Fig. 3C). The exclusively A + T DNA over the central $5 \mathrm{bp}$ is also overtwisted $\left(38.1^{\circ}\right.$ and $36.6^{\circ}$ for F1 and F2, respectively) and exhibits moderately high propeller twisting $\left(-15.0^{\circ}\right.$ and $-15.4^{\circ}$ for $\mathrm{F} 1$ and F2, respectively, compared with $-11.4^{\circ}$ for average B DNA), but not enough to enable bifurcated $\mathrm{H}$ bonding to adjacent bases. The compressed minor groove within the center of the binding site is a critical feature of the DNA structure in the Fis complex, because it enables the two recognition $\mathrm{D} \alpha$-helices of the Fis dimer to insert into adjacent major grooves. The minor groove width increases to $\sim 50 \%$ over its canonical width on the sides opposite to where the Fis recognition helices are inserted, and then again undergoes dramatic compression within the flanking DNA segments (Fig. 3C). These oscillatory changes in minor groove widths are not correlated with appreciable changes in the width of the major groove, even over the region where interactions with the recognition helices induce positive rolls. The expanded minor groove regions fit well with the locations of hypersensitive cleavage sites by DNase I, which binds to wide minor grooves (Suck and Oefner 1986), and the narrow minor groove segments in the center and flanking regions fit with the suppression of hydroxyl radical cleavages that are characteristic of Fis-DNA footprints (Finkel and Johnson 1992; Bokal et al. 1995).

The curvature axis of the DNA over the 17-bp region from -8 to +8 is nearly planar, but the presence of the flanking DNA creates an overall dihedral angle of about $\left(-130^{\circ}\right.$ (Supplemental Fig. S3). The torsion angle deviates out of plane at the edges of the 15-bp core, beginning at the bends at $\mathrm{G}_{-7}-\mathrm{T}_{-6}$ and $\mathrm{G}_{+6}-\mathrm{C}_{+7}$, and the negative dihedral angle is further enhanced in the flanking DNA segments. Fis weakly constrains negative supercoils in vitro, which is incongruent with the sign of the dihedral angle present in the crystals (Travers et al. 2001; Johnson et al. 2005). A more planar curvature axis would also create a better correspondence between DNA-binding properties of mutations at residues making flanking DNA backbone contacts and H-bonding distances (see 


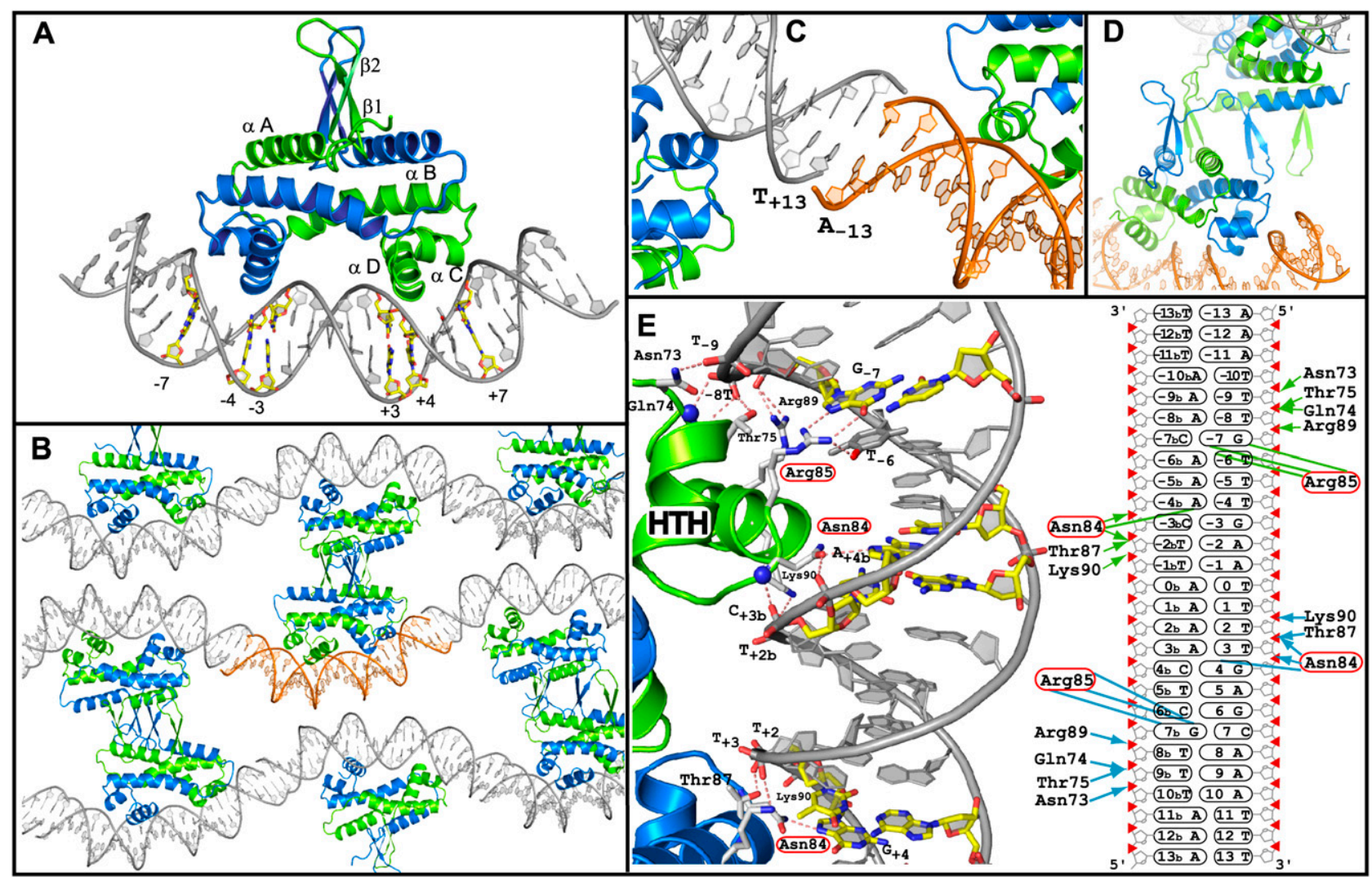

Figure 2. Fis-DNA crystal structure and packing. $(A)$ Fis dimer bound to the F1 sequence. Nucleotides where base identity is important for binding are highlighted in yellow. $(B)$ View of the crystal lattice. The DNA from one asymmetric unit is highlighted in orange. $(C)$ Stacking of DNA ends from adjacent asymmetric units. $(D)$ Interactions between opposing Fis dimers stabilizing the lattice. (E) Fis-DNA contacts in the F1 complex. H bonds to the bases and phosphate backbone are denoted on the structure and ladder representations.

below). It is likely that crystal packing forces are responsible for the presence of the (-) dihedral angles, since the trajectories of the DNA segments flanking the core region are governed by stacking with the adjacent molecules in the lattice (Fig. 2B,C).

\section{Fis-DNA contacts leading to an induced} fit by the DNA

Each HTH unit is anchored within the major groove by nine contacts to the DNA backbone (Fig. 2E). On the outer edges, the side chains of Asn73, Thr75, and Arg89, along with the main chain amide nitrogens of Gln74 and Thr75, are H-bonded to phosphates, enforcing a close approach of the DNA backbone against the sides of Fis. Mutagenesis experiments have shown that the Asn73 side chain plays a particularly important role in DNA binding and bending by Fis. Fis N73A exhibits very poor binding, faster electrophoretic mobilities of DNA complexes, and unusual stiffening of coated single-DNA molecules (Pan et al. 1996; Feldman-Cohen et al. 2006; Skoko et al. 2006). Fis N73S is much less compromised for binding or bending, consistent with the importance of H bonding by the side chain (Pan et al. 1996; McLeod et al. 1999). A more planar DNA axis would decrease the

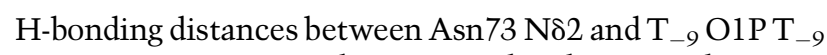
$\mathrm{O} 1 \mathrm{P}$ or $\mathrm{T}_{+9 \mathrm{~b}} \mathrm{O} 1 \mathrm{P}$, and increase the distances between Thr75 O $\gamma$ and $\mathrm{T}_{-8} \mathrm{O} 2 \mathrm{P}$ or $\mathrm{T}_{+8 \mathrm{~b}} \mathrm{O} 2 \mathrm{P}$, which would better fit the severe effect of N73A but mild effect by T75A on binding (Feldman-Cohen et al. 2006; Skoko et al. 2006; Papagiannis et al. 2007). A more planar DNA axis will also increase availability of the Thr75 side chain for cooperative binding with the RNA polymerase $\sigma$ subunit and phage $\lambda$ Xis protein (Papagiannis et al. 2007; Typas et al. 2007). Elimination of the Arg89 side chain severely decreases nonspecific binding and formation of specific complexes with most Fis-binding sites (Osuna et al. 1991; Feldman-Cohen et al. 2006; Skoko et al. 2006). The side chain of Gln74 is not contacting DNA, and thus is available to interact with the RNA polymerase $\alpha$ CTD (Bokal et al. 1997; McLeod et al. 1999).

Three Fis residues-Asn84, Thr87, and Lys90-stabilize the recognition helix D with the DNA backbone strand on the other side of the major groove (Fig. 2E). Of these, mutagenesis has shown that the side chain of Thr87, which is closely linked with the phosphate $(\leq 2.7$ $\AA$ ), is of greatest importance (Koch et al. 1991; Osuna et al. 1991; Pan et al. 1996; Feldman-Cohen et al. 2006). Lys90 is most important for nonspecific binding, and may function by neutralizing the closely approaching 
A

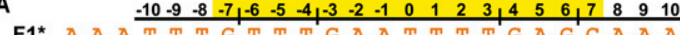

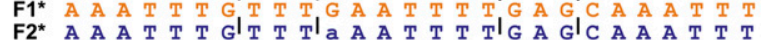
(1)

Figure 3. Structural distortions in the Fis-bound DNA. $(A)$ Roll angle deviations at base-pair steps from the F1 complex structure (orange) and F2 complex structure (blue), as aligned with the sequences on the top. $(B)$ DNA in the F1 structure, with bases important for Fis binding highlighted in green. Red lines schematically represent the DNA helix axis, highlighting the positions of bends. The twist values over the segments denoted in the rectangles are averaged from the F1 structure. (C) Major and minor groove widths for the F1 and F2 structures. Values are between closest phosphates minus their van der Waals surfaces. Dashed lines denote canonical groove widths from DNA fibers (Chandrasekaran and Arnott 1996).

phosphates across the central minor groove (Pan et al. 1994; Feldman-Cohen et al. 2006; Skoko et al. 2006). The main chain amide nitrogen of Asn84 is closely H-bonded with the phosphate of nucleotide $-3 /+3 \mathrm{~b}$ in all structures, but, as discussed below, the side chain adopts different conformations depending on the identity of the base pairs at positions \pm 4 and \pm 3 , and does not contribute significantly to binding to high-affinity sites (Koch et al. 1991; Pan et al. 1994, 1996; Feldman-Cohen et al. 2006). Overall, the DNA backbone contacts fit well with those implicated by ethylation interference experiments (Shao et al. 2008a).

Only two residues from each recognition helix contact bases within the major groove (Fig. 2E). By far the most important is Arg85, whose guanidinium group is positioned to $\mathrm{H}$-bond with the $\mathrm{O} 6$ and $\mathrm{N} 7$ atoms of the conserved $\mathrm{G}_{-7 /+7 \mathrm{~b}}$ at the ends of the 15-bp core-binding sequence (Fig. B). The Arg85 side chain is also H-bonded to the adjacent base at $\mathrm{T}_{-6}\left(\mathrm{O} 4\right.$ atom) and $\mathrm{C}_{+6 \mathrm{~b}}(\mathrm{~N} 4$ atom). Contacts by Arg85 account for the strong DMS protections at guanines when present at positions $-7 /+7_{b}$ and $-6 /+6_{b}$ in Fis-bound complexes, as well as the bends at these positions. Not surprisingly, loss of Arg85 nearly completely abrogates all Fis binding (Koch et al. 1991; Osuna et al. 1991; Feldman-Cohen et al. 2006; Skoko et al. 2006). The side chain of Asn84 (N82) is in position to H-bond with the phosphate and base N7 atoms of $A_{-4 b}$ and $G_{+4}$; the latter is consistent with the protection from DMS attack when a guanine is present at this position. The role of Asn84 in sequence-specific interactions by Fis is discussed further below.

To summarize, Fis directly contacts DNA in the crystal over a 21-bp segment between Asn73 residues (Fig. 2E). The interface includes $3 \mathrm{bp}$ of DNA flanking each side of the 15-bp core, and fits with the minimal length segment required for high-affinity binding and the 21-bp spacing between Fis dimers when nonspecifically coating DNA (Skoko et al. 2006). The interface is stabilized by 18 DNA backbone contacts, of which eight are through main chain contacts with the peptide backbone. As elaborated below, only base contacts with a single residue, Arg85, are important for binding. In the absence of crystal lattice interactions, the flanking DNA in Fis complexes could adopt a range of curvatures that could exceed that in the present crystals. Thus, Arg71, whose side chain is not well resolved in the crystal structures but has been implicated in DNA bending, could be positioned within range of the $-12_{b} /+12$ phosphate (Pan et al. 1996; Bokal et al. 1997; McLeod et al. 1999). On the other hand, Fis interactions with the RNA polymerase $\alpha$ subunit by Arg71 and surrounding residues (Aiyar et al. 2002; McLeod et al. 2002) would require less curvature, but the narrow minor groove within the flanking DNA would enhance $\alpha$ CTDDNA binding (Benoff et al. 2002).

\section{Fis binding to different DNA sequences}

Although Fis-binding sequences are highly variable, sequence alignments and mutational studies have pointed to the importance of three sequence determinants within the 15-bp minimal motif: the conserved $G$ at \pm 7 , the dinucleotide step at $\pm(3-4)$, and the AT-rich central $5 \mathrm{bp}$. To address the mechanism by which each of these segments contributes to Fis recognition, we determined a series of crystal structures of Fis bound to DNAs containing changes within these regions, and discuss how these structures illuminate the mode of DNA target selection by Fis.

The conserved guanine at the boundaries of the 15-bp motif A guanine nucleotide is present at the -7 or $+7_{\mathrm{b}}$ positions in $\sim 90 \%$ of Fis-binding sites. Substitution of both positions essentially abolishes binding (F5 in Fig. 4A; Shao et al. 2008b), but there are many examples of functional Fis sites containing single substitutions. We screened several sequences in an attempt to obtain a crystal structure in which Fis adapted to binding to a site without one or both guanines, and obtained a $3.1 \AA$ structure for the sequence 


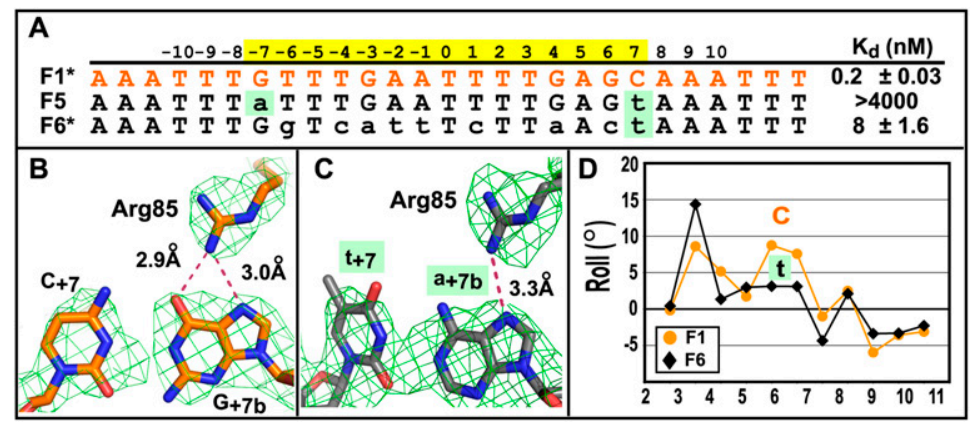

Figure 4. Arg85 contacts with the ends of the corebinding site. (A) Sequences and equilibrium binding constants of substrates containing changes at $\pm 7 .(B)$ Interactions between $\operatorname{Arg} 85$ and $G_{+7 b}$ in the $F 1$ structure. (C) Interaction between Arg85 and $\mathrm{A}_{+7 \mathrm{~b}}$ in the F6 structure. The $2 \mathrm{~F}_{\mathrm{o}}-\mathrm{F}_{\mathrm{c}}$ electron density maps in $B$ and $C$ were contoured at $1.5 \sigma$. $(D)$ Comparison of roll angles between +2 and +11 for the F1 and F6 structures.
F6 (Fig. 4A). F6 shares only 6 of 15 bp in common with the F1 sequence, with the most important difference being an A substitution for the $G$ at $+7 \mathrm{~b}$. In the high-affinity $F 1$ structure, the $\operatorname{Arg} 85 \mathrm{H}$-bonds with both $\mathrm{O} 6$ and $\mathrm{N} 7$ of $\mathrm{G}_{+7 \mathrm{~b}}$ (Fig. 4B) as well as $\mathrm{O} 4$ of $\mathrm{C}_{+6 \mathrm{~b}}$, whereas in the $\mathrm{F} 6$ complex, Arg85 is in position to only weakly contact $A_{+7 b}$ N7 (Fig. 4C). All other Fis-DNA contacts observed with F1 remain in the F6 structure. However, the conformations of the bases are altered over the mutant interface (Fig. 4D; Supplemental Fig. S4). The roll deviation at $+(6-7)$ is decreased from $9^{\circ}$ to $3^{\circ}$, and the roll angle at $+(3-4)$ is increased from $8^{\circ}$ to $14.5^{\circ}$. Thus, a sequence that is missing the conserved guanine molds to the Fis surface in a manner that changes local DNA conformations but retains the other proteinDNA contacts.

Minor groove compression and the AT-rich central region The central $5 \mathrm{bp}$ of the DNA interface are not contacted by Fis, but compression of the minor groove within this segment is essential for insertion of the recognition helices within adjacent major grooves. The DNA within the central region of high-affinity Fis sites is AT-rich, including a propensity for $\mathrm{A}_{4-6}$ tracts. Indeed, Cho et al. (2008) recently reported a strong preference $\left(\mathrm{E}_{\mathrm{val}}=10^{-82}\right)$ for $\mathrm{A}$ tracts among 900 Fis-binding sites in the Escherichia coli chromosome. We investigated the effects of different AT sequences and the presence of G/C base pairs on Fis binding and the structures of the bound complexes.

A tracts and $A_{n} T_{n}$ segments behave in solution as if they contain a static bend into the minor groove at their center (Crothers and Shakked 1999). Crystal and NMR structures have given mixed results, with molecules showing straight helical axes, small bends (negative rolls) into the minor groove, or small bends at the junctions (Hud and Plavec 2003; Haran and Mohanty 2009). $\mathrm{T}_{\mathrm{n}} \mathrm{A}_{\mathrm{n}}$ sequences do not contain a static bend in solution or in atomic structures, although T-A steps are highly flexible. Most studies show narrow minor grooves over AT-rich segments, but high-resolution structures of some AT sequences, particularly those containing one or more T-A steps, have been reported to display widened minor grooves (Mack et al. 2001; Stefl et al. 2004; Woods et al. 2004). Fis binding to the F1 or F2 sequences containing central $A_{n} T_{n}$ segments generate $K_{d}$ values of $0.2 n M$ and dissociation rates of 23 and $52 \mathrm{~min}$, respectively (Figs. 1C, $5 \mathrm{~A})$. Binding sites containing a central A tract (F26) or T tract (A tract on the bottom strand, F24) also give similar subnanomolar binding constants and lifetimes with the Fis complex formed, with F24 being somewhat more stable than F1 or F26 (Fig. 5A). Binding to the sequence containing the TTAAA segment (F25) is slightly diminished but still robust. In contrast, binding by the human papilloma virus (HPV) E2 protein to a site in which its noncontacted AT-rich spacer is substituted by TTAA instead of AATT is reduced 20-fold (Hegde 2002).

Crystal structures of Fis bound to F24 (3.1 A), F25 (3.1 $\AA)$, and F26 (3.15 $⿱$ A) are nearly identical. Minor groove width variations closely parallel those observed for the F1 structure, with widths reduced to almost $3 \AA$ at the center (Fig. 5B). The central 5-bp steps exhibit small negative roll deviations ranging from $0^{\circ}$ to $-7^{\circ}$ and little overall curvature (Fig. 5C,F). The central DNA segments in each structure are overwound (average twist values are $37^{\circ}-38^{\circ}$, and the base pairs display moderately enhanced propeller twisting averaging $-13^{\circ}$ to $-15^{\circ}$ (Fig. 5F). We conclude that each of the AT-rich sequences is capable of readily conforming to a similar Fis-bound structure with a highly compressed central minor groove.

The effects on Fis binding of GC substitutions within the central DNA segment are also given in Figure 5A. Introduction of a single $\mathrm{C} / \mathrm{G}$ at the center (F27) has no measurable effect on Fis binding, and the $3.05 \AA$ structure of the complex is nearly indistinguishable from F1 (Fig. $5 \mathrm{~A}, \mathrm{D}-\mathrm{F})$. Thus, the presence of a single $\mathrm{C} / \mathrm{G}$ in an otherwise AT-rich segment does not appear to be energetically limiting compression of the minor groove by Fis. However, three G/C base pairs (F28), or especially substitution of all five central base pairs with G/C (F29), severely decrease Fis binding (Fig. 5A). Even though Fis binding to F29 was $\sim 700$-fold poorer than to F1, we obtained a $3.1 \AA$ resolution crystal of the complex. Compression of the central minor groove in the F29 complex was severely compromised (Fig. 5D; Supplemental Fig. S5). Only the width of the central $2 \mathrm{bp}$ is reduced below average B DNA values, whereas the minor groove of high-affinity Fis complexes is narrowed over $6 \mathrm{bp}$. The central 5-bp steps are also much less propeller-twisted in F29 than in the F1 complex (average $=-9^{\circ}$ vs. $\left.-15^{\circ}\right)$ (Fig. 5F). The G/C center remains relatively unbent, with an overall curvature of $2.7^{\circ}$ (Fig. $5 \mathrm{E}, \mathrm{F})$. We conclude that the presence of multiple GC base pairs in the center is unfavorable for Fis binding because of the increased conformational cost of compressing the minor groove. 
Stella et al.
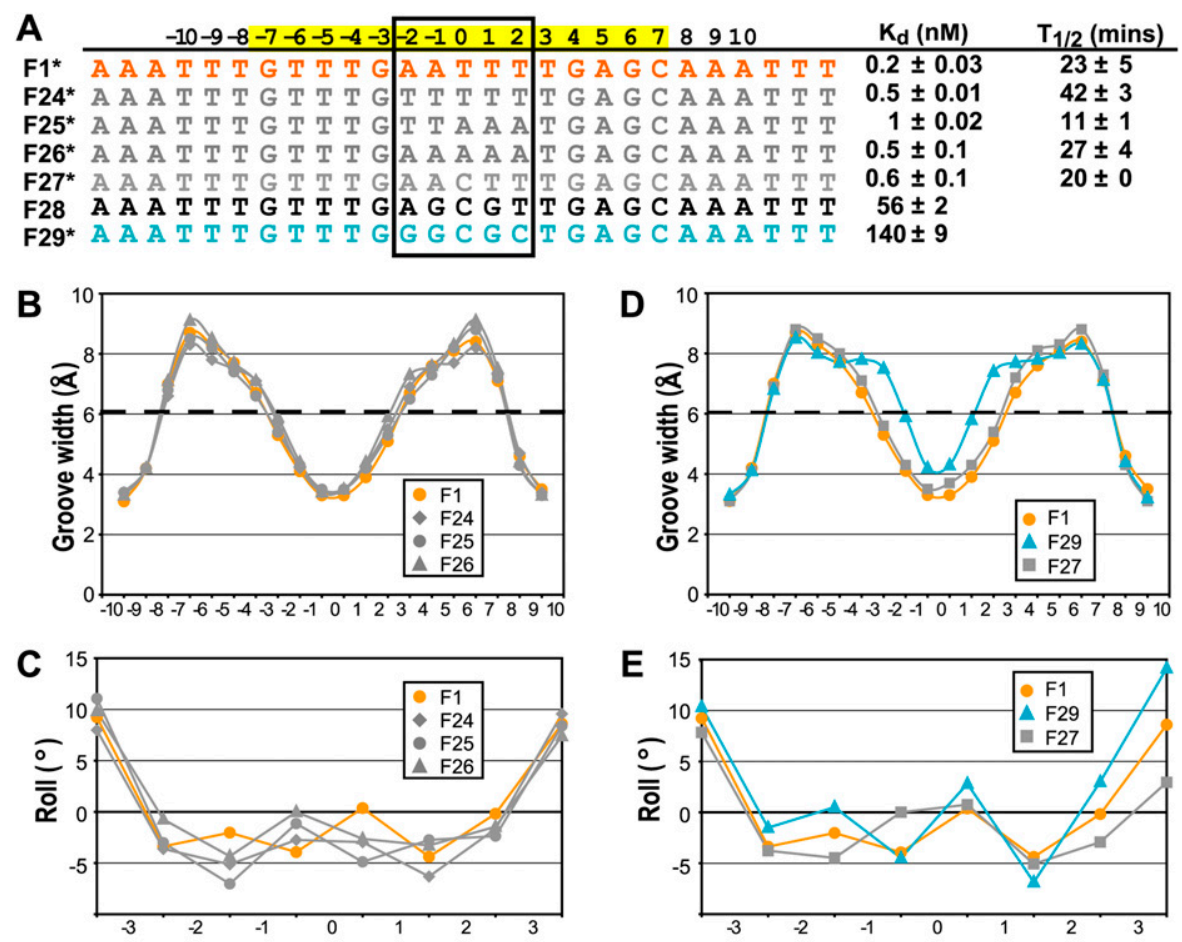

\begin{tabular}{lrrrrrr}
-2 to $+2(5$ bp $)$ & F1 & F24 & F25 & F26 & F27 & F29 \\
\hline Average twist $\left({ }^{\circ}\right)$ & 38 & 38 & 37 & 37 & 36 & 37 \\
Average propeller twist $\left(^{\circ}\right)$ & 15.1 & 14.0 & 13.5 & 12.8 & 12.8 & 9.0 \\
Curvature $\left({ }^{\circ}\right)$ & 1.7 & 2.4 & 2.6 & 2.9 & 2.6 & 2.7 \\
Average minor groove width $(\AA)$ & 3.9 & 4.1 & 4.1 & 4.3 & 4.3 & 5.5 \\
Minimum minor groove width $(\AA)$ & 3.3 & 3.4 & 3.5 & 3.4 & 3.5 & 4.2
\end{tabular}

Figure 5. DNA substitutions within the Fis-binding site center. $(A)$ Sequences of Fis-binding substrates together with equilibrium binding constants and half-lives. $(B)$ Minor groove widths of complexes with AT centers. $(C)$ Roll angles over the central segments of complexes with AT centers. $(D)$ Minor groove widths of complexes containing GC substitutions. $(E)$ Roll angles over the central segments of complexes with GC substitutions. $(F)$ DNA parameters over the central 5-bp segments between -2 and +2 .

The $\pm(3-4)$ base-pair step High-affinity Fis-binding sites often have a Y-R dinucleotide step at the $\pm(3-4)$ positions, which are at the positions of DNA backbone contacts by Asn84 and Thr87. Y-R steps exhibit the poorest stacking, and thus are often positions of helix deformation /Olson et al. 1998; Dickerson 1999). In the F1 and F2 structures, these dinucleotide steps (TG/CA or TA) display modest peaks of positive roll and accompanying twist values down to $26^{\circ}$. The minor groove over the region is dramatically narrowing toward the minimum at the center of the binding site, and the $\pm(3-4)$ steps over the left half-sites exhibit significant changes in translational base-stacking parameters (Supplemental Fig. S3).

Although the -4 and +4 positions are most often a $\mathrm{Y}$ and $\mathrm{R}$, respectively, $-4 \mathrm{G}$ and $+4 \mathrm{C}$ are represented among native Fis-binding sites, and introducing these changes into the $\mathrm{F} 1$ sequence only reduces equilibrium binding $\sim 10$-fold (F18) (Fig. 6A; Shao et al. 2008b). These substitutions create $\mathrm{G}-\mathrm{G}$ and $\mathrm{T}-\mathrm{C}$ at the $\pm(3-4)$ steps, but the Y-R steps T-G/C-A are present at the adjacent dinucleotides $\pm(4-5)$. A $3.1 \AA$ structure of Fis bound to F18 reveals that the DNA structure changes significantly over the major groove interfaces to adapt to this sequence. The DNA bends shift such that the roll deviation on each half- site is now greatest at the new Y-R steps at $-(5-4)$ and $+(4-5)$. For example, on the right half-site, an $18^{\circ} \mathrm{kink}$ is now present at $\mathrm{C}_{+4}-\mathrm{A}_{+5}$, and the rolls at $+(3-4)(\mathrm{T}-\mathrm{C}$ in F18) and $+(6-7)$ present in the $\mathrm{F} 1$ structure are reduced to just $3^{\circ}$ and $8.5^{\circ}$, respectively (Fig. 6E; Supplemental Fig. S6C). The accompanying changes in twist and slide combine to extend the central region of minor groove compression such that the groove between -3 and +3 is narrowed to $<4 \AA$ (Fig. 6F; Supplemental Fig. S6A,B). Unlike the optimal situation when the Asn84 side chain is proximal to N7 of a purine (Fig. 6B), in the F18 structure, Asn 84 is not in position to $\mathrm{H}$-bond with either the base or the phosphate at $\mathrm{C}_{-4 \mathrm{~b} /+4}$ (Fig. 6C). However, the close contacts to $\mathrm{P}_{-3 \mathrm{~b} /+3}$ by Asn 84 main chain amide and Thr87 $\mathrm{O} \gamma$, as well as the other interactions that exist in the F1 structure, are maintained.

Fis binding is severely compromised when a thymine is located at $-4 \mathrm{~b}$ and +4 (Shao et al. 2008b), as reflected by the 2500 -fold reduction in equilibrium binding to the F19 sequence (Fig. 6A). The $3.1 \AA$ structure of Fis bound to F23 (which contains a thymine at +4 ) provides a structural explanation for its inhibitory effect. The thymine 5 -methyl clashes with the normal position of the Asn84 side chain, effectively pushing it away from the DNA (Fig. 


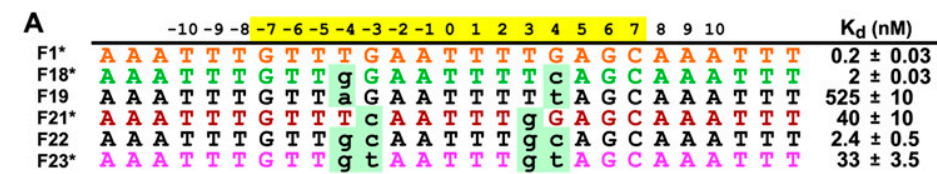

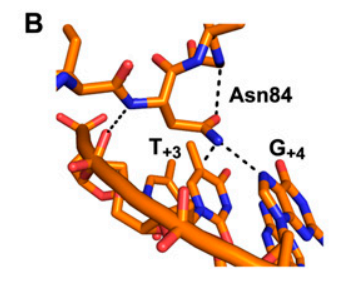
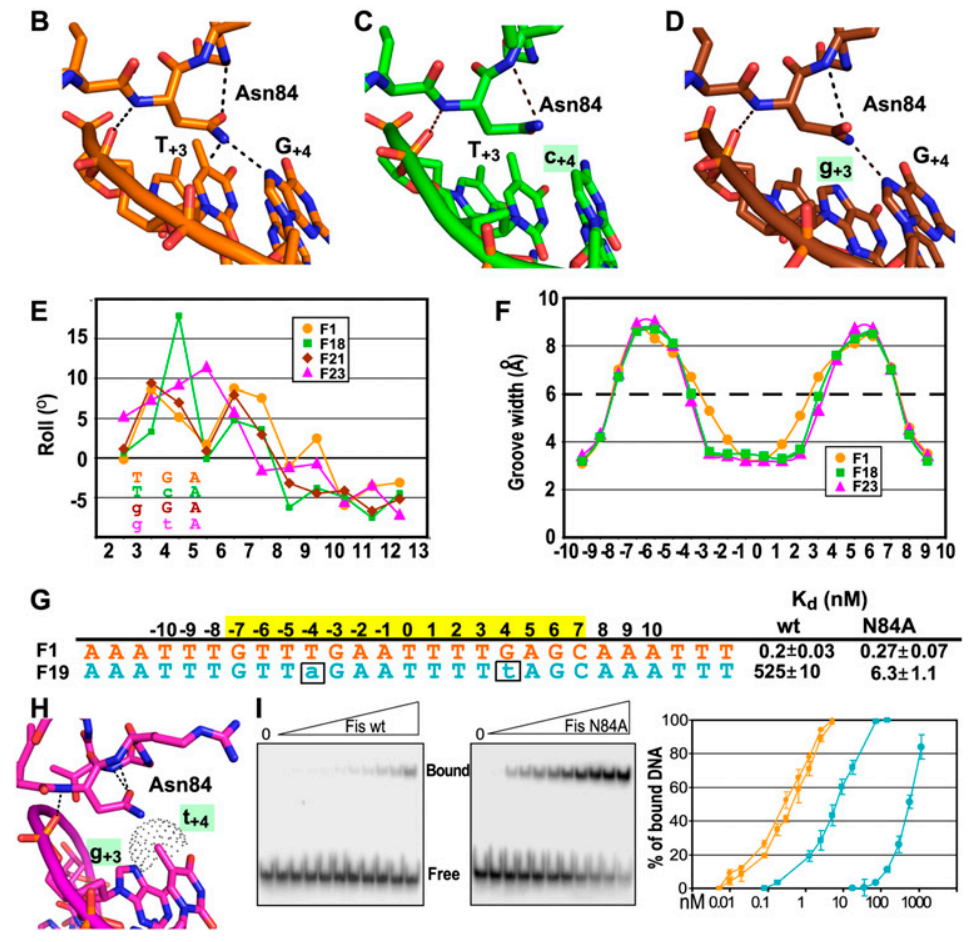
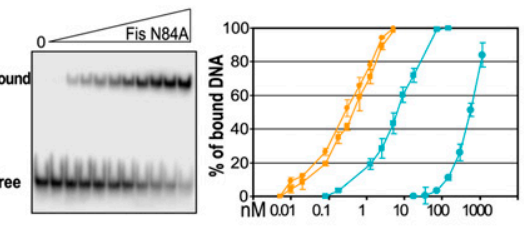

Figure 6. DNA substitutions within the $\pm(3-4)$ positions of the Fis-binding site. $(A)$ Sequences of Fis-binding substrates and equilibrium binding constants. $(B)$ View of the Asn84-DNA contacts in the right half of the F1 complex. $(C)$ The Asn84-DNA contacts over the same region in the F18 complex (G-to-C mutation at +4$)$. (D) The Asn84-DNA contacts over the same region in the F21 complex (T-to-G mutation at +3 ). (E) Plot of roll angles over the right half of the F1, F18, F21, and F23 DNA structures. (F) Minor groove widths for the F1, F18, and F23 structures. $(G)$ Sequence and equilibrium binding constants for Fis-wt and Fis-N84A binding to F19 containing the symmetrical mutations at \pm 4 that position a T proximal to the $\mathrm{N} 84$ side chain. $(H)$ Structure of the Fis-F23 complex highlighting Asn84 over the region containing a G-to-T mutation at +4 , as well as a T-to-G change at +3 . The van der Waals surface of the $T_{+4}$ methyl, which disrupts the position of the Asn 84 side chain, is displayed. (I) EMSAs on the F19 duplex oligonucleotide using twofold increasing amounts of Fis-wt and N84A mutant proteins beginning with $0.08 \mathrm{nM}$. On the right are binding isotherms of Fis-wt (circles) and FisN84A (squares) binding to the F1 (orange) or F19 (blue) DNA substrates.
$6 \mathrm{H})$. The DNA in the major groove interface on the right side of the F23 complex adopts a very different structure with $(+)$ roll deviations between $5^{\circ}$ and $12^{\circ}$ throughout the segment between +2 and +7 (Fig. 6E). Moreover, the central region of minor groove compression is extended in a similar manner as in the F18 complex (Fig. 6F). To confirm that the clash between the Asn84 side chain and $\mathrm{T}_{+4}$ methyl is responsible for the extremely poor binding, we asked whether Fis-N84A would bind to the F19 sequence with enhanced affinity compared with wild-type Fis. As shown in Figure 6, G and I, equilibrium binding by the Fis mutant to F19 is increased $>80$-fold. Binding of FisN84A to the optimal F1 sequence is nearly identical to that of wild-type Fis, indicating that interactions with a purine base (when present) and phosphate by the Asn 84 side chain provide little binding energy. We conclude that the most important feature of the Asn84 side chain is to discriminate against a thymine at positions $-4 \mathrm{~b} /+4$.

High-affinity Fis-binding sites exhibit a large preference for $\mathrm{a}-3 \mathrm{R}$ and $+3 \mathrm{Y}$, yet there is no contact by Fis to the base. The presence of a nonconsensus base on both half-sites can result in a $>1000$-fold decrease in binding affinity (Shao et al. 2008b), but in some sequence contexts (e.g., F22) (Fig. 6A), a C at -3 and a $\mathrm{G}$ at +3 are tolerated reasonably well. $-3 \mathrm{~A}$ and $+3 \mathrm{~T}$ are somewhat more frequently represented over $-3 \mathrm{G}$ and $+3 \mathrm{C}$ among native binding sites, and although there is no detectable difference in equilibrium binding, an A rather than a $\mathrm{G}$ at -3 increases the lifetime of the Fis-DNA complex (F1 vs. F2) (Fig. 1C). The structures of the DNAs in the F1 and F2 complexes are nearly identical (Fig. 3), but an AT-rich central segment that extends to the \pm 3 positions is predicted to have an increased propensity for minor groove compression, and therefore may require less energy to conform to the Fis-bound structure (discussed below). The F21 DNA contains the nonconsensus $-3 \mathrm{C}$ and $+3 \mathrm{G}$ substitutions and exhibits 200fold poorer binding than F1 (Fig. 6A). Surprisingly, the $2.9 \AA$ structure of the Fis-F21 complex is also similar to F1, with the roll deviations through the major groove interfaces nearly paralleling each other (Fig. 6D,E). Apparently, without an easily deformable base-pair step within the major groove interface, Fis conforms the F21 sequence into a shape that largely matches that of the optimal binding sequence, although the 200-fold lower affinity implies that this must take considerable binding energy. When a Y-R step is present at $\pm(4-5)$, as is the case for F22, binding to a sequence containing a $\mathrm{C} / \mathrm{G}$ at $-3 /+3$ is only reduced 12 -fold from F1. Alternative locations for a flexible Y-R step within the major groove interface of regulatory Fis sites have been proposed previously (Lazarus and Travers 1993).

\section{Intrinsic properties of the DNA structure direct Fis binding}

As discussed above, a critical feature of the DNA in the Fisbound complex is the compression of the central AT-rich minor groove, which allows the recognition $\alpha$-helices of each Fis subunit to insert into adjacent major grooves. We 
wished to first understand which structural parameters of the DNA helix are responsible for changing the conformation of the minor groove in the Fis-bound complex. Second, we asked whether the intrinsic properties of the sequence based on naked DNA crystal structures could predict a DNA shape that qualitatively conformed to the Fisbound structure, and thus could predict Fis binding efficiency.

The 3DNA suite of Lu and Olson (2008) was used to build synthetic DNA models using parameters obtained from the F1 complex structure. DNA built with 12 basepair and base-pair step parameters generates a DNA structure that closely matches the molecule in the crystal structure (RMSD $=0.02 \AA)$. The in silico DNA has the same curvature, and the width changes by the minor groove largely parallel those of the F1 structure (Fig. 7A,B). DNA built with average parameter values for B DNA, except for the specific roll deviations from the F1 structure, almost entirely reproduce the overall curvature from the crystal structure. DNA molecules constructed with only the roll or twist values from the crystal structure generate the variable minor groove width profile of the Fis complex, albeit the amplitude, particularly with respect to center compression, was less (Fig. 7A; Supplemental Fig. S7). Combining roll and twist parameters from the F1 structure increased the magnitude of minor groove compression and expansion. Even though slide alone did not reproduce the overall minor groove width profile of the crystal structure (data not shown), addition of slide to roll or twist parameters further increased compression of the central minor groove (Fig. 7A,F; Supplemental Fig. S7), and the combination of just roll, twist, and slide replicated the minor groove width variations of the F1 structure to nearly the same extent as DNA built using all 12 parameters (Fig. $7 \mathrm{~A}, \mathrm{~B}, \mathrm{~F})$.

To determine whether the intrinsic structure of the F1 sequence was predisposed to adopt the changes in minor groove widths present in the Fis complex, DNA was built using average sequence-dependent dinucleotide step parameters compiled from high-resolution crystal structures of naked DNA (Olson et al. 1998). The profile of the resulting minor groove widths resembles that of the F1 crystal structure, albeit the amount of the compression and expansion is less (Fig. 7C). As with the DNA built with the F1 crystal structure parameters, dinucleotide values of roll, twist, and slide are sufficient to largely

\begin{tabular}{lrrc} 
A & $\begin{array}{c}\text { RMSD } \\
(\AA)\end{array}$ & $\begin{array}{c}\text { Curvature } \\
\left({ }^{\circ}\right)\end{array}$ & $\begin{array}{c}\text { Minimum minor } \\
\text { groove width }(\AA)\end{array}$ \\
\hline F1 crystal & & 65 & 3.3 \\
B-DNA & 4.8 & 0 & 6.9 \\
F1 model & 0.02 & 65 & 3.3 \\
Roll only & 1.5 & 63 & 5.7 \\
Twist only & 4.8 & 0 & 5.6 \\
Slide only & 3.6 & 1.5 & 5.8 \\
Roll and Twist & 1.5 & 65 & 4.4 \\
Roll and Slide & 1 & 64 & 4.9 \\
Twist and Slide & 3.6 & 1 & 4.7 \\
Roll, Twist, and Slide & 0.8 & 66 & 3.7
\end{tabular}

B

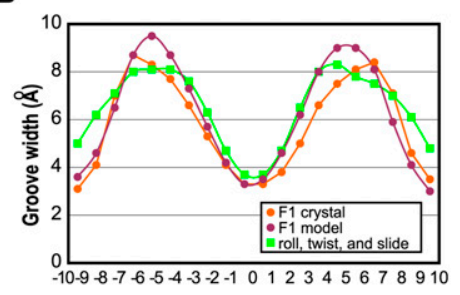

C

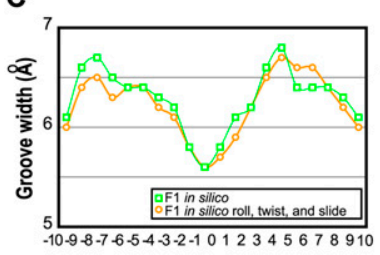

D

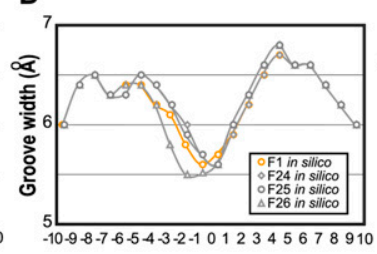

E

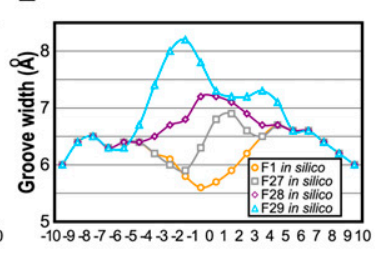

$\mathbf{F}$

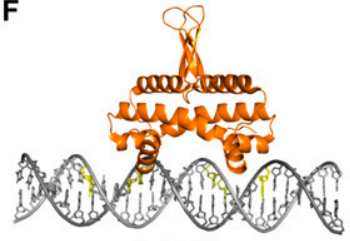

F1 B-DNA

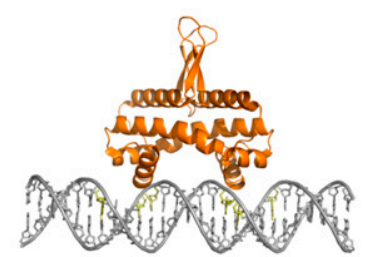

F1 twist and slide

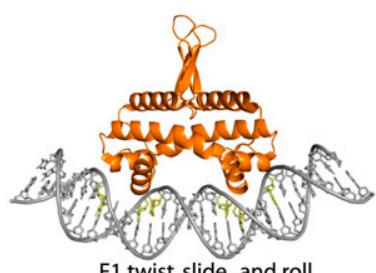

F1 twist, slide, and roll
Figure 7. Structures of in silico DNA models. (A) Summary of DNA features of in silico models representing the F1 complex. RMSD (angstroms) refers to a leastsquares alignment of the models with DNA residues -12 to +12 of the F1 complex crystal structure. The minimum minor groove width is the narrowest distance within the DNA center. F1 crystal is the DNA from the crystal structure, B DNA is the F1 sequence DNA model constructed from average B DNA parameters, and F1 model is the DNA model constructed from all 12 parameters from the $\mathrm{F} 1$ crystal structure (see the Materials and Methods); the remaining entries reflect DNA constructed using average B DNA parameters, except for the listed parameter(s) from the F1 crystal structure. Thus, "Roll only" incorporates the individual rolls from the crystal structure, and "Roll, Twist, and Slide" incorporate those three values from each base-pair step in the crystal structure. $(B)$ Plot of minor groove widths of the F1 crystal structure (orange), the F1 model using all 12 parameters (magenta), and the model using only roll, twist, and slide (green). Additional plots of models listed

in $A$ are provided in Supplemental Figure S7. $(C)$ Minor groove widths of models representing the intrinsic structure of the F1 sequence using sequence-specific values for roll, twist, slide, shift, tilt, and rise (orange), or values for only roll, twist, and slide (green), together with average values for the other parameters. $(D)$ Minor groove widths of models representing the intrinsic structure of the Fis-binding sites with different AT centers. Analogous plots of the DNA in the Fis-bound complex are in Figure 5B. $(E)$ Minor groove widths of models representing the intrinsic structure of the Fis-binding sites with central G/C substitutions. Plots of the F27 and F29 DNA in Fisbound complexes are in Figure 5D. In $D$ and $E$ DNA models were constructed using the six sequence-specific dinucleotide parameters. $(F, l e f t)$ Docking of the Fis dimer onto canonical B DNA such that the HTH on the right side is inserted into the major groove, but the left HTH clashes with the DNA. (Middle) Docking of Fis onto DNA constructed with the twist and slide parameters of the F1 complex, achieving a partial fit of both HTH motifs into the major groove. (Right) Addition of the F1 roll parameters to the DNA in the middle panel, generating a close fit $(\mathrm{RMSD}=0.8 \AA$ ) with the DNA in the F1 crystal structure. 
replicate the profile obtained using all 12 parameters. There is little resemblance between intrinsic bends present in the model DNA generated in silico and bending in the Fis-bound crystal structure (Supplemental Fig. S8). These results strongly suggest that an unbound DNA sequence representing a high-affinity Fis binding site adopts a minor groove shape that already qualitatively corresponds to the Fis-bound structure; the intrinsic curvature of the DNA appears less important for targeting Fis binding.

To test the hypothesis that sequence-directed changes in minor groove widths are a critical feature of Fis recognition, in silico DNA structures of sequences corresponding to those in our Fis-DNA crystal structures were generated. Figure 7D shows the modeled minor groove profiles for the series of AT-rich sequences. The minor groove width profiles appear remarkably similar, with the central minor grooves being compressed to about the same extent regardless of whether the sequence is an $\mathrm{A}$ tract (F26), $T$ tract (top strand, F24), $A_{n} T_{n}(F 1)$, or $T_{n} A_{n}$ (F25), consistent with their robust Fis-binding properties and nearly identical structures in the complex. Introduction of a single $\mathrm{G} / \mathrm{C}$ base pair into the center of the sequence (F27) generated an in silico structure that only partially corresponded to the minor groove profile of $\mathrm{F} 1$ (Fig. 7E). Because this substitution had little measurable affect on Fis binding, and the structure of the F27 complex was nearly indistinguishable from $\mathrm{F} 1$, we suggest that this sequence can still readily adopt the Fis-bound structure. Substitution of three or five $\mathrm{G} / \mathrm{C}$ base pairs into the center of the F1 sequence resulted in major disruptions to the minor groove width profiles (Fig. 7E). In these cases, the modeled intrinsic minor groove width was expanded over the center, thus accounting for the very poor Fis binding by these sequences, and the shortened compressed segment observed in the F29 structure bound by Fis (Fig. 5D). These results imply that increasing numbers of $\mathrm{G} / \mathrm{C}$ base pairs within the center of the Fis-binding site generate structures that do not conform to the spacing of the recognition helices on the Fis dimer, and thus become increasingly energetically costly for Fis binding.

Sequence changes at $\pm(3-4)$ are also modeled to affect minor groove width profiles. For example, the presence of a $-3 \mathrm{C}$ and $+3 \mathrm{G}$ (F21) strongly disrupts the profile over the left half of the binding site (Supplemental Fig. S9). The F18 sequence containing $-4 \mathrm{G}$ and $+4 \mathrm{C}$ is modeled to contain an intrinsically larger region of narrow groove compression extending into the right half, consistent with the larger region of minor groove compression in the Fis-bound structure (Fig. 6F; Supplemental Fig. S9). Thus, effects on intrinsic minor groove shape, in addition to the importance of a bendable Y-R sequence, appears to contribute to the sequence preferences at the $\pm(3-4)$ positions and the structure of the DNA in the Fis-bound complexes.

\section{Discussion}

Target site search and assembly of stable Fis-DNA complexes

Our Fis-DNA crystal structures and molecular modeling suggest the following pathway for DNA target selection by Fis (see Fig. 7F). Fis initially searches for a DNA segment containing an intrinsically narrow minor groove where AT composition, not sequence, is the key determinant. This enables insertion of its recognition $\alpha$-helices into the adjacent major grooves where $\mathrm{H}$ bonding between Fis and the DNA backbone and the base at \pm 7 coordinates an induced fit, with accompanying bending by the DNA to stabilize the complex. The stabilities of the complexes and structures of the DNA interfaces within the major groove are governed by the sequencedependent bending propensity of DNA (e.g., the location of YR steps), the identity of the base at $-7 /+7 \mathrm{~b}$ (preferably a guanine), and the absence of a thymine at $-4 \mathrm{~b} /+4$. Depending on the $15-\mathrm{bp}$ core sequence, the DNA adopts overall curvatures ranging from $60^{\circ}$ to $75^{\circ}$ in the crystals, with additional conformational flexibility within the DNA flanking the primary interface likely to occur in solution.

Bending of DNA by Fis is critical for its role in DNA compaction and as a specific regulator of various DNA reactions. For example, Fis-induced bends are required for assembly of invertasomes that catalyze site-specific DNA inversion, for assembly of intasomes that mediate viral excision, and for creating alternative promoter structures that control transcription. Mutually compatible DNA shape changes may contribute to cooperative binding between Fis and partners like the $\sigma$ and $\alpha$ (CTD) subunits of RNA polymerase and phage $\lambda$ Xis, which bind immediately adjacent to Fis on DNA, and where only a small number of amino acid residues on each protein are involved.

\section{Intrinsic DNA shape contributes to indirect recognition by other DNA-binding proteins}

There is increasing evidence that intrinsic DNA shape, in addition to sequence-specific deformability, can play a large role in targeting protein to specific DNA segments by indirect recognition mechanisms. One well-studied example that bears some structural relationships to Fis is the HPV E2 protein (Hegde 2002). Although the E2 protein does not contain HTH DNA-binding motifs like Fis, the two proteins share the unusual feature that their recognition $\alpha$-helices that insert into the major groove are positioned much closer to each other than the pitch of canonical B DNA. The intervening spacer DNA is also not contacted by the E2 protein, yet the nucleotide sequence strongly modulates binding affinity. However, unlike Fis, the E2 spacer region adapts by a combination of bending (up to $45^{\circ}$ ) into the minor groove and compression (down to $2.7 \AA$ ) of the minor groove. Current evidence indicates that the presence of both a preformed bend (or bending flexibility) and an intrinsically narrow minor groove targets E2 binding (Hegde 2002; Zhang et al. 2004).

Narrow minor grooves have been found recently to contain enhanced negative electrostatic potentials, which stabilize insertion of arginines in a variety of protein-DNA complexes (Rohs et al. 2009). Well-studied examples are Hox protein family members, which discriminate between related binding sites by inserting arginine or other basic 
side chains into minor grooves that exhibit unique electrostatic surface potentials as a function of their sequence (Joshi et al. 2007). For the Fis protein, the unusually narrow minor groove enables interactions by residues from the two fixed-spaced HTH domains into adjacent major grooves without amino acid contacts into the central minor groove.

DNA shape differences controlling protein binding are not limited to the minor groove. A recent report found that intrinsic width variations of the major groove of the Met repressor-binding sequence closely correlated with the bound structure (Locasale et al. 2009).

Radical changes in DNA groove widths are a particularly prominent feature of complexes formed by prokaryotic and eukaryotic chromatin-associated DNA-bending proteins, such as members of the HU/IHF and HMGB families, and histones (Johnson et al. 2008). Unlike Fis, these proteins primarily contact DNA over the minor groove, but like Fis, they all use a preponderance of nonspecific DNA backbone contacts. Proteins such as IHF and the HMGB family members SRY, LEF1, and Sox2 that exhibit modest sequence specificity support some $\mathrm{H}$ bonding with bases, analogous to the single arginine-base contact formed by each Fis subunit. Indirect recognition mechanisms figure prominently in target selection by all of these architectural proteins, and it is likely that part of the indirect recognition mechanisms involves conformational flexibility of groove widths.

\section{Materials and methods}

\section{Fis-DNA binding assays}

Fis protein and DNA duplexes for binding assays and crystallography were prepared as described in the Supplemental Material. Gel mobility shift assays (EMSA) were performed in $20-\mu \mathrm{L}$ reactions containing $20 \mathrm{mM}$ HEPES (pH 7.5), $150 \mathrm{mM} \mathrm{NaCl}$, $10 \%$ glycerol, $500 \mu \mathrm{g} / \mathrm{mL}$ BSA, $50 \mu \mathrm{g} / \mathrm{mL}$ poly dI-dC (Promega), $1 \mathrm{mM}$ DTT, $0.1 \mathrm{mM}$ EDTA, and $5 \mathrm{fmol}$ of ${ }^{32} \mathrm{P}$-end-labeled probe. For oligonucleotide probes, incubation was for $\geq 10 \mathrm{~min}$ at $4^{\circ} \mathrm{C}$ prior to applying to a $10 \%$ polyacrylamide gel $(19: 1)$ in $0.5 \times \mathrm{TBE}$ at $4{ }^{\circ} \mathrm{C} . \mathrm{K}_{\mathrm{d}}$ values were determined as described previously /Chiu et al. 2002). Decay of prebound Fis complexes was measured by addition of $500 \mu \mathrm{g} / \mathrm{mL}$ unlabeled $\mathrm{F} 1$ duplex to binding reactions where $50 \%-70 \%$ of the labeled probe was initially bound by Fis. At various times, aliquots were applied to the gel, the percent complexes remaining at different times were determined, and a $\mathrm{T}_{1 / 2}$ was calculated from the resulting plot.

\section{Crystallization and structure determination}

Details of the crystallization and structure determination are provided in the Supplemental Material. In brief, crystals of FisDNA complexes were grown at $4^{\circ} \mathrm{C}$ using a $1: 1$ mixture of complex and reservoir $(0.2-0.3 \mathrm{M}$ Na citrate, $0.1 \mathrm{M}$ Tris- $\mathrm{HCl}$ at $\mathrm{pH} 8.5,36 \%-40 \%$ PEG 400 [v/v]) and flash-frozen in liquid nitrogen. Data were collected at $100 \mathrm{~K}$ at the Advanced Light Source (Berkeley CA) beamline 8.2.1 and the Advanced Photon Source (Chicago IL) beamline 24-ID-C (Table 1; Supplemental Table S1). The complexes containing the F1 or F2 DNA were solved independently by molecular replacement (PHASER) (McCoy et al. 2007) using the $1.9 \AA$ Fis-R71L structure (PDB code $1 \mathrm{ETO}$ ) as the search model. The DNA was fit into the electron density by iterative cycles of refinement (REFMAC 5.2) (Murshudov et al. 1997) and model building (COOT) (Emsley and Cowtan 2004). Anisotropy scaling was performed using the NIH Diffraction Anisotropy Server (http://www.doe-mbi.ucla.edu/ $\sim$ sawaya/anisoscale) (Strong et al. 2006), and a mild translocation defect was corrected by the procedure of Wang et al. (2005). The models were refined using CNS_SOLVE (Brunger et al. 1998), PHENIX (Adams et al. 2002), and REFMAC 5.2 (Murshudov et al. 1997). A composite omit map and final $2 F_{o}-F_{c}$ map for the F1 complex are given in Supplemental Figure S10. The final F1 and F2 models contain the 27-bp DNA plus a Fis dimer, with chain A beginning at residue 8 and a complete chain B (residues 1-98). Structures of nine additional Fis-DNA complexes containing different base-pair substitutions were solved by molecular replacement using the F1 complex as the search model and refined as above. Refinement statistics are given in Table 1 and Supplemental Table S1. Figures were generated using PyMol (http://www.pymol.org).

\section{DNA structure analysis and modeling}

DNA base-pair parameters and groove widths were analyzed using 3DNA (Lu and Olson 2003). Bending was evaluated using CURVES (Lavery and Sklenar 1988) and 3DNA-MADBEND (Lu and Olson 2003), and dihedral angles were measured with the torsion tool in COOT (see Supplemental Fig. S3 for details). The DNA rebuild software in the 3DNA package (Lu and Olson 2008) was used to construct in silico models of DNA using specified values of propeller twist, buckle, opening, shear, stretch, stagger, roll, tilt, twist, shift, slide, and rise. Averaged overall and specific base-pair and base-pair step parameters were from Olson et al. (1998, 2001).

\section{Acknowledgments}

We thank Drs. Todd Yeates, Michael Sawaya, Yingssu Tsai, and Jiyong Park (UCLA) for critical comments and suggestions regarding the lattice translocation defect, and Drs. Hanna Yuan (Academia Sinica, Taipei) and Dick Dickerson (UCLA) for comments on the manuscript. We thank the UCLA-DOE X-ray Crystallography Core Facility, which is supported by DOE Grant DE-FC02-02ER63421. We also thank C. Ralston for help with X-ray data collection at ALS beamline 8.2.1. We thank M. Capel, K. Rajashankar, N. Sukumar, Jonathan Schuermann, and I. Kourinov at the NECAT beamline 24-ID-C at APS. This work was supported by NIH grant GM038509. The ALS and BCSB are supported by DOE Grant DE-AC02-05CH11231 and the NIH. Use of the APS is supported by the DOE under Contract DEAC02-06CH11357.

\section{References}

Adams PD, Grosse-Kunstleve RW, Hung LW, Ioerger TR, McCoy AJ, Moriarty NW, Read RJ, Sacchettini JC, Sauter NK, Terwilliger TC. 2002. PHENIX: Building new software for automated crystallographic structure determination. Acta Crystallogr D Biol Crystallogr 58: 1948-1954.

Aiyar SE, McLeod SM, Ross W, Hirvonen CA, Thomas MS, Johnson RC, Gourse RL. 2002. Architecture of Fis-activated transcription complexes at the Escherichia coli $\operatorname{rrnB} \mathrm{P} 1$ and rrnE P1 promoters. I Mol Biol 316: 501-516.

Ball CA, Osuna R, Ferguson KC, Johnson RC. 1992. Dramatic changes in Fis levels upon nutrient upshift in Escherichia coli. J Bacteriol 174: 8043-8056.

Benoff B, Yang H, Lawson CL, Parkinson G, Liu J, Blatter E, Ebright YW, Berman HM, Ebright RH. 2002. Structural basis 
of transcription activation: The CAP- $\alpha$ CTD-DNA complex. Science 297: 1562-1566.

Bokal AJ, Ross W, Gourse RL. 1995. The transcriptional activator protein FIS: DNA interactions and cooperative interactions with RNA polymerase at the Escherichia coli rmB P1 promoter. J Mol Biol 245: 197-207.

Bokal AJ, Ross W, Gaal T, Johnson RC, Gourse RL. 1997. Molecular anatomy of a transcription activation patch: FISRNA polymerase interactions at the Escherichia coli rrnB P1 promoter. EMBO I 16: 154-162.

Bruist MF, Glasgow AC, Johnson RC, Simon MI. 1987. Fis binding to the recombinational enhancer of the Hin DNA inversion system. Genes \& Dev 1: 762-772.

Brunger AT, Adams PD, Clore GM, DeLano WL, Gros P, GrosseKunstleve RW, Jiang JS, Kuszewski J, Nilges M, Pannu NS, et al. 1998. Crystallography \& NMR system: A new software suite for macromolecular structure determination. Acta Crystallogr D Biol Crystallogr 54: 905-921.

Chandrasekaran R, Arnott S. 1996. The structure of B-DNA in oriented fibers. I Biomol Struct Dyn 13: 1015-1027.

Cheng YS, Yang WZ, Johnson RC, Yuan HS. 2000. Structural analysis of the transcriptional activation region on Fis: Crystal structures of six Fis mutants with different activation properties. J Mol Biol 302: 1139-1151.

Chiu TK, Sohn C, Dickerson RE, Johnson RC. 2002. Testing water-mediated DNA recognition by the Hin recombinase. EMBO J 21: 801-814.

Cho BK, Knight EM, Barrett CL, Palsson BO. 2008. Genomewide analysis of Fis binding in Escherichia coli indicates a causative role for A-/AT-tracts. Genome Res 18: 900910.

Crothers DM, Shakked Z. 1999. DNA bending by adeninethymine tracts. In Oxford handbook of nucleic acid structure (ed. S Neidle), pp. 455-470. Oxford University Press, Oxford.

Dickerson RE. 1999. Helix structure and molecular recognition by B-DNA. In Oxford handbook of nucleic acid structure (ed. S Neidle), pp. 1-23. Oxford University Press, Oxford.

Dorman CJ. 2009. Nucleoid-associated proteins and bacterial physiology. Adv Appl Microbiol 67: 47-64.

Emsley P, Cowtan K. 2004. Coot: Model-building tools for molecular graphics. Acta Crystallogr D Biol Crystallogr 60: 2126-2132.

Feldman-Cohen LS, Shao Y, Meinhold D, Miller C, Colon W, Osuna R. 2006. Common and variable contributions of Fis residues to high-affinity binding at different DNA sequences. J Bacteriol 188: 2081-2095.

Finkel SE, Johnson RC. 1992. The Fis protein: It's not just for DNA inversion anymore. Mol Microbiol 6: 3257-3265.

Haran TE, Mohanty U. 2009. The unique structure of A-tracts and intrinsic DNA bending. Q Rev Biophys 42: 41-81.

Hegde RS. 2002. The papillomavirus E2 proteins: Structure, function, and biology. Annu Rev Biophys Biomol Struct 31: 343-360.

Hengen PN, Bartram SL, Stewart LE, Schneider TD. 1997. Information analysis of Fis binding sites. Nucleic Acids Res 25: 4994-5002.

Hubner P, Arber W. 1989. Mutational analysis of a prokaryotic recombinational enhancer element with two functions. EMBO I 8: 577-585.

Hud NV, Plavec J. 2003. A unified model for the origin of DNA sequence-directed curvature. Biopolymers 69: 144-158.

Johnson RC, Johnson LM, Schmidt JW, Gardner JF. 2005. Major nucleoid proteins in the structure and function of the Escherichia coli chromosome. In The bacterial chromosome (ed. NP Higgins), pp. 65-132. ASM Press, Washington, DC.
Johnson RC, Stella S, Heiss JK. 2008. Bending and compaction of DNA by proteins. In Protein-nucleic acid interactions (eds. PA Rice, CC Correll), pp. 176-220. RSC Press, Cambridge, UK.

Joshi R, Passner JM, Rohs R, Jain R, Sosinsky A, Crickmore MA, Jacob V, Aggarwal AK, Honig B, Mann RS. 2007. Functional specificity of a Hox protein mediated by the recognition of minor groove structure. Cell 131: 530-543.

Koch C, Ninnemann O, Fuss H, Kahmann R. 1991. The $\mathrm{N}$-terminal part of the E. coli DNA binding protein FIS is essential for stimulating site-specific DNA inversion but is not required for specific DNA binding. Nucleic Acids Res 19: 5915-5922.

Kostrewa D, Granzin J, Koch C, Choe HW, Raghunathan S, Wolf W, Labahn J, Kahmann R, Saenger W. 1991. Three-dimensional structure of the E. coli DNA-binding protein FIS. Nature 349: 178-180.

Lavery R, Sklenar H. 1988. The definition of generalized helicoidal parameters and of axis curvature for irregular nucleic acids. I Biomol Struct Dyn 6: 63-91.

Lazarus LR, Travers AA. 1993. The Escherichia coli FIS protein is not required for the activation of $\operatorname{tyr} T$ transcription on entry into exponential growth. EMBO J 12: 2483-2494.

Locasale JW, Napoli AA, Chen S, Berman HM, Lawson CL. 2009. Signatures of protein-DNA recognition in free DNA binding sites. I Mol Biol 386: 1054-1065.

Lu XJ, Olson WK. 2003. 3DNA: A software package for the analysis, rebuilding and visualization of three-dimensional nucleic acid structures. Nucleic Acids Res 31: 5108-5121.

Lu XJ, Olson WK. 2008. 3DNA: A versatile, integrated software system for the analysis, rebuilding and visualization of threedimensional nucleic-acid structures. Nat Protoc 3: 12131227.

Mack DR, Chiu TK, Dickerson RE. 2001. Intrinsic bending and deformability at the T-A step of CCTTTAAAGG: A comparative analysis of T-A and A-T steps within A-tracts. J Mol Biol 312: 1037-1049.

McCoy AJ, Grosse-Kunstleve RW, Adams PD, Winn MD, Storoni LC, Read RJ. 2007. Phaser crystallographic software. I Appl Crystallogr 40: 658-674.

McLeod SM, Xu J, Cramton SE, Gaal T, Gourse RL, Johnson RC. 1999. Localization of amino acids required for Fis to function as a class II transcriptional activator at the RpoS-dependent proP P2 promoter. J Mol Biol 294: 333-346.

McLeod SM, Aiyar SE, Gourse RL, Johnson RC. 2002. The C-terminal domains of the RNA polymerase $\alpha$ subunits: Contact site with Fis and localization during co-activation with CRP at the Escherichia coli proP P2 promoter. I Mol Biol 316: 517-529.

Merickel SK, Sanders ER, Vazquez-Ibar JL, Johnson RC. 2002. Subunit exchange and the role of dimer flexibility in DNA binding by the Fis protein. Biochemistry 41: 5788-5798.

Murshudov GN, Vagin AA, Dodson EJ. 1997. Refinement of macromolecular structures by the maximum-likelihood method. Acta Crystallogr D Biol Crystallogr 53: 240-255.

Olson WK, Gorin AA, Lu XI, Hock LM, Zhurkin VB. 1998. DNA sequence-dependent deformability deduced from proteinDNA crystal complexes. Proc Natl Acad Sci 95: 11163-11168.

Olson WK, Bansal M, Burley SK, Dickerson RE, Gerstein M, Harvey SC, Heinemann U, Lu XJ, Neidle S, Shakked Z, et al. 2001. A standard reference frame for the description of nucleic acid base-pair geometry. J Mol Biol 313: 229-237.

Osuna R, Finkel SE, Johnson RC. 1991. Identification of two functional regions in Fis: The $\mathrm{N}$-terminus is required to promote Hin-mediated DNA inversion but not $\lambda$ excision. $E M B O$ J 10: 1593-1603. 
Pan CQ, Feng JA, Finkel SE, Landgraf R, Sigman D, Johnson RC. 1994. Structure of the Escherichia coli Fis-DNA complex probed by protein conjugated with 1,10-phenanthroline copper(I) complex. Proc Nat1 Acad Sci 91: 1721-1725.

Pan CQ, Finkel SE, Cramton SE, Feng JA, Sigman DS, Johnson RC. 1996. Variable structures of Fis-DNA complexes determined by flanking DNA-protein contacts. J Mol Biol 264: 675-695.

Papagiannis CV, Sam MD, Abbani MA, Yoo D, Cascio D, Clubb RT, Johnson RC. 2007. Fis targets assembly of the Xis nucleoprotein filament to promote excisive recombination by phage $\lambda$. J Mol Biol 367: 328-343.

Perkins-Balding D, Dias DP, Glasgow AC. 1997. Location, degree, and direction of DNA bending associated with the Hin recombinational enhancer sequence and Fis-enhancer complex. I Bacteriol 179: 4747-4753.

Rohs R, West SM, Sosinsky A, Liu P, Mann RS, Honig B. 2009. The role of DNA shape in protein-DNA recognition. Nature 461: 1248-1253.

Safo MK, Yang WZ, Corselli L, Cramton SE, Yuan HS, Johnson RC. 1997. The transactivation region of the Fis protein that controls site-specific DNA inversion contains extended mobile $\beta$-hairpin arms. EMBO J 16: 6860-6873.

Shao Y, Feldman-Cohen LS, Osuna R. 2008a. Biochemical identification of base and phosphate contacts between Fis and a high-affinity DNA binding site. J Mol Biol 380: 327-339.

Shao Y, Feldman-Cohen LS, Osuna R. 2008b. Functional characterization of the Escherichia coli Fis-DNA binding sequence. J Mol Biol 376: 771-785.

Skoko D, Yoo D, Bai H, Schnurr B, Yan J, McLeod SM, Marko JF, Johnson RC. 2006. Mechanism of chromosome compaction and looping by the Escherichia coli nucleoid protein Fis. $I$ Mol Biol 364: 777-798.

Stefl R, Wu H, Ravindranathan S, Sklenar V, Feigon J. 2004. DNA A-tract bending in three dimensions: Solving the dA4T4 vs. dT4A4 conundrum. Proc Natl Acad Sci 101: $1177-1182$.

Strong M, Sawaya MR, Wang S, Phillips M, Cascio D, Eisenberg D. 2006. Toward the structural genomics of complexes: Crystal structure of a PE/PPE protein complex from $\mathrm{Myco}$ bacterium tuberculosis. Proc Natl Acad Sci 103: 8060-8065.

Suck D, Oefner C. 1986. Structure of DNase I at $2.0 \AA$ resolution suggests a mechanism for binding to and cutting DNA. Nature 321: 620-625.

Travers A, Muskhelishvili G. 2005. Bacterial chromatin. Curr Opin Genet Dev 15: 507-514.

Travers A, Schneider R, Muskhelishvili G. 2001. DNA supercoiling and transcription in Escherichia coli: The FIS connection. Biochimie 83: 213-217.

Typas A, Stella S, Johnson RC, Hengge R. 2007. The -35 sequence location and the Fis- $\sigma$ factor interface determine $\sigma^{\mathrm{S}}$ selectivity of the proP $(\mathrm{P} 2)$ promoter in Escherichia coli. Mol Microbiol 63: 780-796.

Ussery D, Larsen TS, Wilkes KT, Friis C, Worning P, Krogh A, Brunak S. 2001. Genome organisation and chromatin structure in Escherichia coli. Biochimie 83: 201-212.

Wang J, Kamtekar S, Berman AJ, Steitz TA. 2005. Correction of $\mathrm{X}$-ray intensities from single crystals containing latticetranslocation defects. Acta Crystallogr D Biol Crystallogr 61: 67-74.

Woods KK, Maehigashi T, Howerton SB, Sines CC, Tannenbaum S, Williams LD. 2004. High-resolution structure of an extended A-tract: [d(CGCAAATTTGCG)]2. I Am Chem Soc 126: $15330-15331$.

Yuan HS, Finkel SE, Feng JA, Kaczor-Grzeskowiak M, Johnson RC, Dickerson RE. 1991. The molecular structure of wild- type and a mutant Fis protein: Relationship between mutational changes and recombinational enhancer function or DNA binding. Proc Natl Acad Sci 88: 9558-9562.

Zhang Y, Xi Z, Hegde RS, Shakked Z, Crothers DM. 2004. Predicting indirect readout effects in protein-DNA interactions. Proc Natl Acad Sci 101: 8337-8341. 


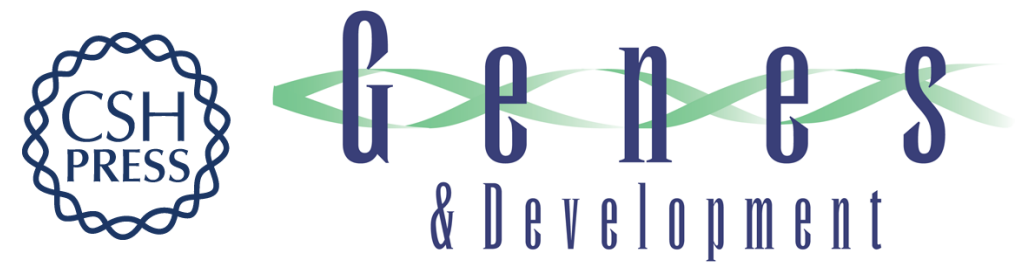

\section{The shape of the DNA minor groove directs binding by the DNA-bending protein Fis}

Stefano Stella, Duilio Cascio and Reid C. Johnson

Genes Dev. 2010, 24:

Access the most recent version at doi:10.1101/gad.1900610

\section{Supplemental http://genesdev.cshlp.org/content/suppl/2010/04/12/24.8.814.DC1 Material}

References This article cites 58 articles, 15 of which can be accessed free at: http://genesdev.cshlp.org/content/24/8/814.full.html\#ref-list-1

\section{License}

Email Alerting

Receive free email alerts when new articles cite this article - sign up in the box at the top Service

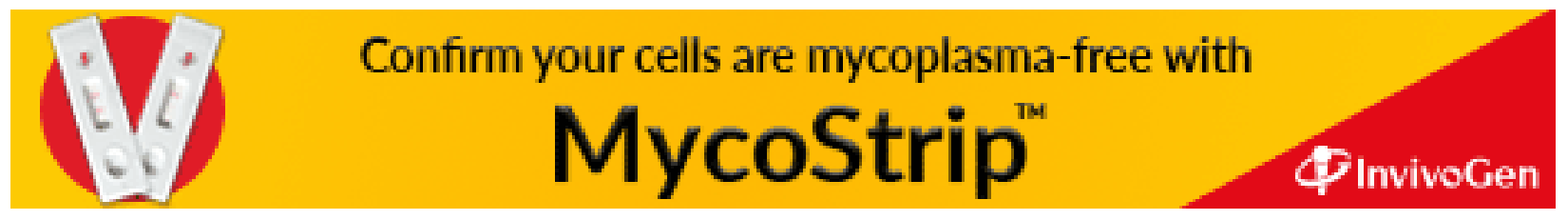

